\title{
Sea-ice growth in Ongul Strait, Antarctica
}

\author{
Toshiyuki KaWamura, Kay I. OHshima, \\ Institute of Low Temperature Science, Hokkaido University, Sapporo 060, Japan \\ SYUKI USHIO, \\ National Institute of Polar Research, Tokyo 173, Japan \\ TAKATOSHI TAKIZAWA \\ Japan Marine Science and Technology Center, Yokosuka 237, Japan
}

\begin{abstract}
A two-year study was conducted on the growth processes of sea ice in Ongul Strait, Antarctica. Routine measurements of snow depth and ice thickness were made and sea-ice cores were collected to assess their structure, temperature and salinity. The snow depth varied from 0 to about $1 \mathrm{~m}$. In the winter months, the growth rate is higher in bare-ice regions than in snow-covered regions. However, over the year, the ice thickness itself is lower in the bare-ice regions than in the snowcovered regions. Sea ice in the snow-covered regions increased in thickness in spring rather than in winter, due to the formation of snow-ice and by ice formation related to the melting of snow cover.
\end{abstract}

\section{INTRODUCTION}

Sea ice has a marked influence on interactions between the ocean and atmosphere of the polar regions. An existing ice cover markedly changes the surface albedo, reduces the exchange of heat, water vapor and momentum across the air-sea interface, and redistributes salt in the ocean. Hence, the anomalies and variations in sea ice are considered to have a great impact on regional and global climate.

Knowledge of basic sea-ice properties throughout the year is important in order to understand their effects on the polar environment and the growth history and processes experienced by the sea ice. Sea-ice observations in the Antarctic regions were obtained first in the austral summer (e.g. Gow and others, 1982; Clarke and Ackley, 1984; Lange, 1988). Recently, intensive analyses of sea ice during the austral winter have revealed the development and physical properties of sea ice in the central and eastern Weddell Sea (Wadhams and others, 1987; Lange and others, 1989; Eicken and Lange, 1989; Lange and others, 1990; Lange and Eicken, 1991). However, observations of the growth process and properties of sea ice throughout the complete annual cycle are rare.

The Japanese Antarctic Research Expedition (JARE) conducted a five-year program around Syowa Station from 1987 to 1991 to evaluate atmosphere/sea-ice/ocean interaction. The effects of sea-ice growth on the water structure of an ice-covered ocean have also been considered. Year-round observations were made from 1990 to 1991 to clarify the growth processes of sea ice. In this paper, we present the preliminary analyses of sea-ice processes observed in Ongul Strait near Syowa Station.

\section{OBSERVATIONS}

Lützow-Holm Bay is a typical fast-ice covered region facing the open Southern Ocean. Four main observation points (OS1-OS4) and four additional points $(7,8,10$ and 11) were used across the strait (Fig. 1). Monthly observations of snow depth and ice thickness were made at the four main points April-December 1990 (except for August and October). In 1991, we observed the height of snow stakes, snow depth and sea-ice thickness at all the stations every month from March to December. We also obtained $75 \mathrm{~mm}$ diameter sea-ice core samples several times at the main stations. Temperatures of the cores were measured in situ approximately every $100 \mathrm{~mm}$ before the cores were packed in polyethylene bags and transported to a cold room kept below $-25^{\circ} \mathrm{C}$. Great care was taken to

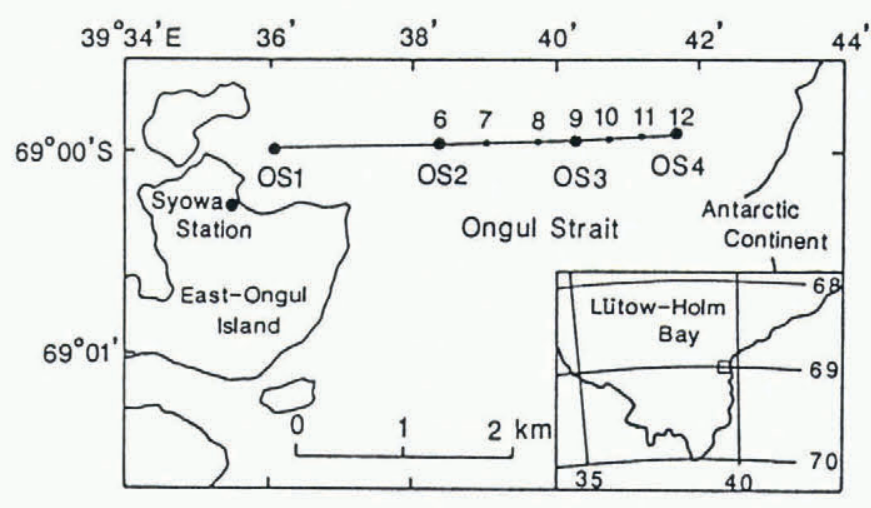

Fig. 1. Observation points in Ongul Strait near Syowa Station. 
lose as little of the brine as possible. Some core samples were analyzed at Syowa Station, while the others were shipped to the Institute of Low Temperature Science for further analysis.

The sea-ice cores were analyzed as follows: Cores were split lengthwise, producing vertical sections about $5 \mathrm{~mm}$ thick, with horizontal sections also prepared at intervals of $100-200 \mathrm{~mm}$. These thick sections allowed us to examine bubble and brine-layer distributions and the structure of brine channels under scattered light. The thick sections were smoothed by planing to $1 \mathrm{~mm}$ thickness to enable the identification of individual grains and substructure in the grains. Thus, we could classify the entire length of the cores according to their structure. Following the structural analysis, the cores were cut horizontally at intervals of $50-100 \mathrm{~mm}$ and salinity of the melt samples was determined with a refractometer.

\section{RESULTS AND DISCUSSION}

\section{Snow depth and sea-ice thickness}

Figure 2 shows variations of snow depth and sea-ice thickness from April 1990 to December 1991 at three locations. The measured values of snow depth and ice thickness at one location varied by about $0.1 \mathrm{~m}$, especially with more snow cover. Comparing the snow depth for both years, a difference was found at OS4, which in 1991 was covered with little snow but in 1990 recorded a maximum depth of $0.25 \mathrm{~m}$. The snow depth at OS3 was similar in both years, but a slight difference was recognized in the accumulating season. At OS2 the snow depth in 1991 was approximately $0.1-0.2 \mathrm{~m}$ less than in 1990 .

Figure 3a shows the spatial variation of snow depth across Ongul Strait. The snow depth changes drastically over a few kilometers, increasing with distance from the continent. These results show that OS4, the sample point nearest the continent, is located in a bare ice zone, the point OS2 is covered with snow throughout the year, and OS3 is not snow-covered during the summer months. Therefore, the strait is a suitable area to examine the role of snow cover in sea-ice growth.

Sea-ice thicknesses at OS3 and OS4 changed with similar tendencies in both years as shown in Figure 2. Therefore, the maximum snow cover of about $0.25 \mathrm{~m}$ in 1990 at OS4 may have had no influence on sea-ice thickness. A more detailed examination, however, reveals that during the austral winter months in 1991, when there was no snow, the growth rate at OS4 was higher than that at the other sites which had snow. Consequently, it is most likely that the snow cover affected the sea-ice growth.

Growth of sea ice at OS2 was, moreover, affected significantly by its deep snow cover: the sea ice at that point grew very little from March to September (Fig. 2a). On the contrary, the growth of sea ice was recognizable even after austral winter. In particular, in 1990, the thickness increased by $0.26 \mathrm{~m}$ in one month from November to December. This increase in thickness probably resulted from the formation of "infiltration ice" or snow-ice. The submergence of sea ice below the sea level takes place under the increasing weight of the
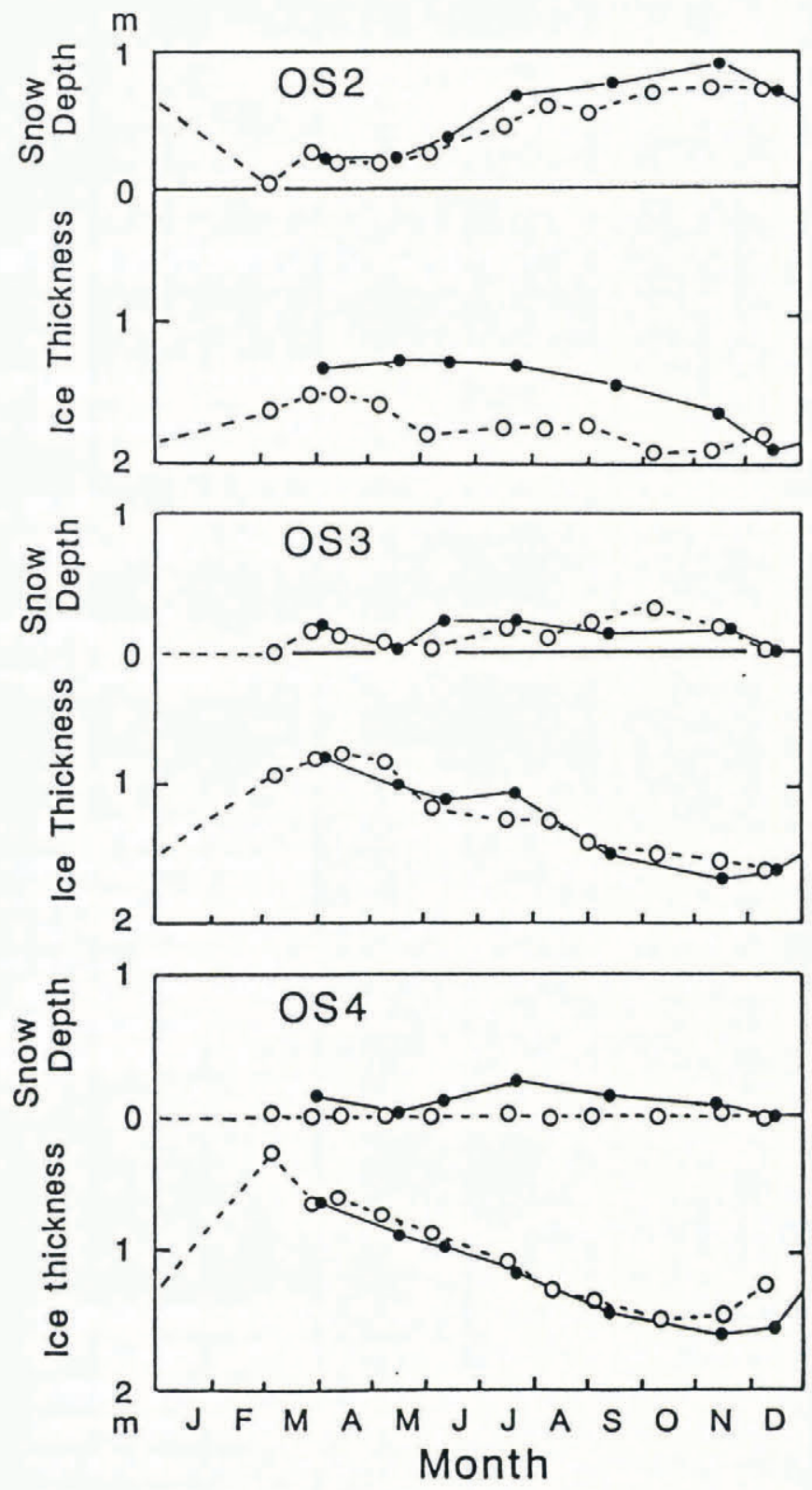

Fig. 2. Seasonal variation of snow depth and ice thickness at OS2, OS3 and OS4 in 1990 (solid line) and 1991 (broken line).

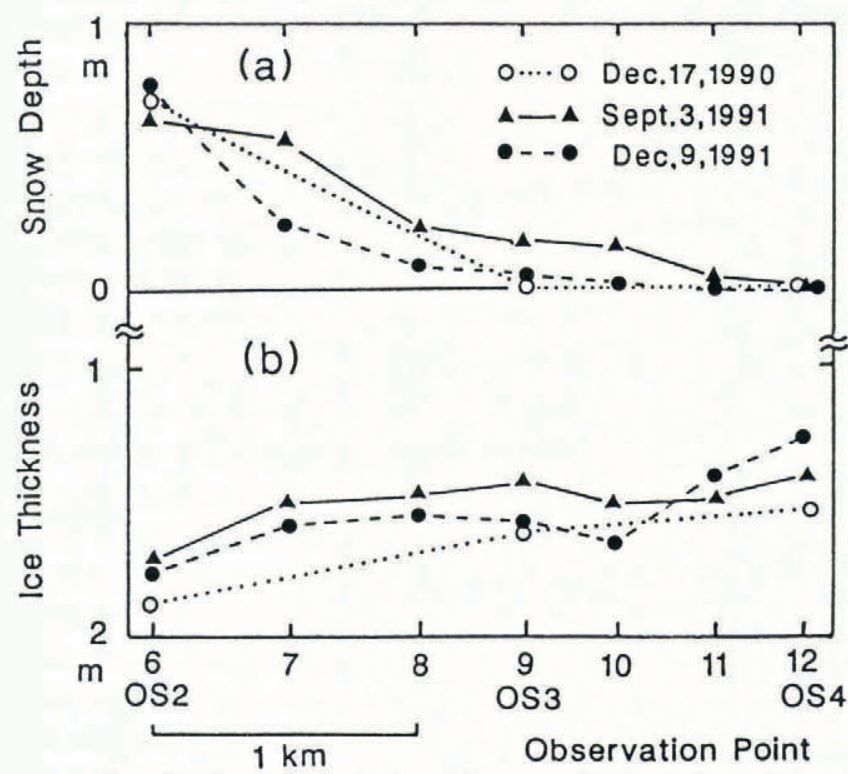

Fig. 3. Spatial variation of snow depth. (a) and ice thickness (b) across Ongul Strait on three representative sampling days. 
OS2

Mar.5 Apr.12 Aug.9 Oct.11

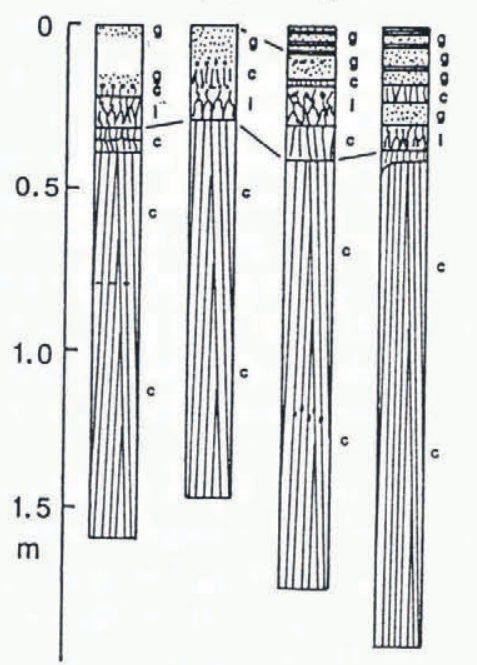

OS 3

Apr.12 Aug.8 Oct.11

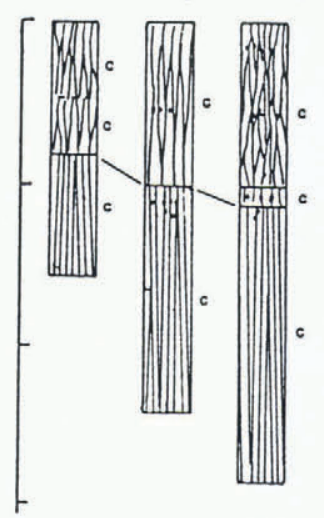

OS 4

Mar.5 Mar.28 Apr.12 Aug.9 Oct.11 Dec.9

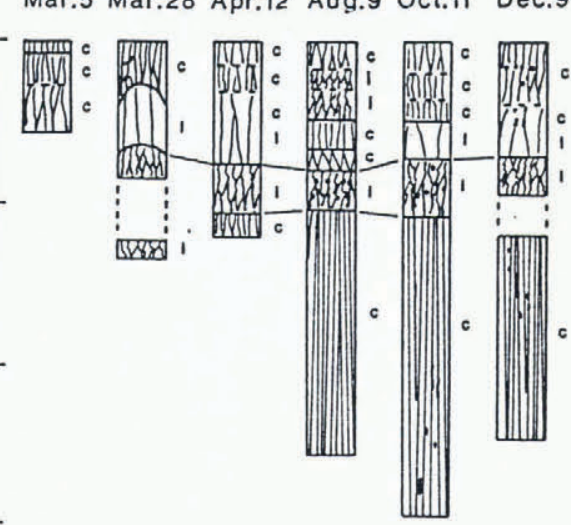

Fig. 4. Seasonal variation of stratigraphy of sea-ice cores collected at OS2, OS3 and OS4 in 1991. c, columnar ice; $g$, granular ice; $i$, intermediate columnar/granular ice; and l, large single crystalline ice.

snow cover. Consequently, sea water enters the snow cover and freezes to form snow-ice. In the summer seasons, meltwater from the snow cover may also contribute to snow-ice formation. Because the ice draft was not measured in 1990, the sea level could not be determined with reference to the snow/ice interface. Calculation based on a simple hydrostatic balance shows that ice thickness was less than the ice draft after June. The ice thickness data of OS2 in 1991 shows that sea ice grew slightly faster from September to October than in the other months. Except for December, the measured ice draft was a few centimeters less than the ice thickness throughout the year. Based upon the draft measurements, snow ice could not be formed, yet examination of the structure indicates that about $0.1 \mathrm{~m}$ of snow ice formed between April and August.

An interesting relationship was detected between snow depth and sea-ice thickness. As shown in Figure 3, the increase of snow depth and ice thickness are parallel. This result is in contrast to the hypothesis that a thick snow cover reduces the vertical heat flux through the ice and accordingly reduces the growth rate due to bottom freezing. On the other hand, the heavier snow load could accelerate growth of the ice cover by the formation of snow-ice. Lange and others (1990) have reported that the snow cover in the Weddell Sea generally enhances the overall ice thickness throughout the austral winter months. However, alternative mechanisms may also be proposed in our case. Because deeper snow cover prevents sea ice from melting in summer at OS2, the decrease in ice thickness is not as great (Fig. 2a) and no internal melting has been observed. It is also likely that meltwater from the snow cover enhances sea-ice growth.

In regions with more snow cover, the sea-ice thickness increased even after November and reached its maximum thickness in December (with the exception of OS2 in 1991). It is therefore most probable that the snow cover delays the time of the maximum ice thickness. This fact is related not only to the transformation of snow into snowice but also to the decreased melting of the bottom and inner layers of sea ice by oceanic heat flux and solar radiation, respectively. Further analysis of their effects is necessary to clarify the mechanism.

Stake length was observed to increase in bare-ice regions, e.g. two stakes at OS4 increased 50 and $60 \mathrm{~mm}$ in length at a nearly constant rate from March to October. A similar increase was also detected at observation point 11. These increments suggest that the ice surface was depressed by surface evaporation in the entire bare-ice region throughout the year.

\section{Structure and salinity of sea ice}

Figure 4 demonstrates the seasonal variation of stratigraphy of sea-ice cores collected in 1991 at OS2, OS3 and OS4. The variation of the salinity profile in each core is shown in Figure 5. Sea ice in Ongul Strait melted away completely in February 1989 and reformed in April. The ice survived in the austral summer melt season of 1990 and subsequently grew as shown in Figure 2.

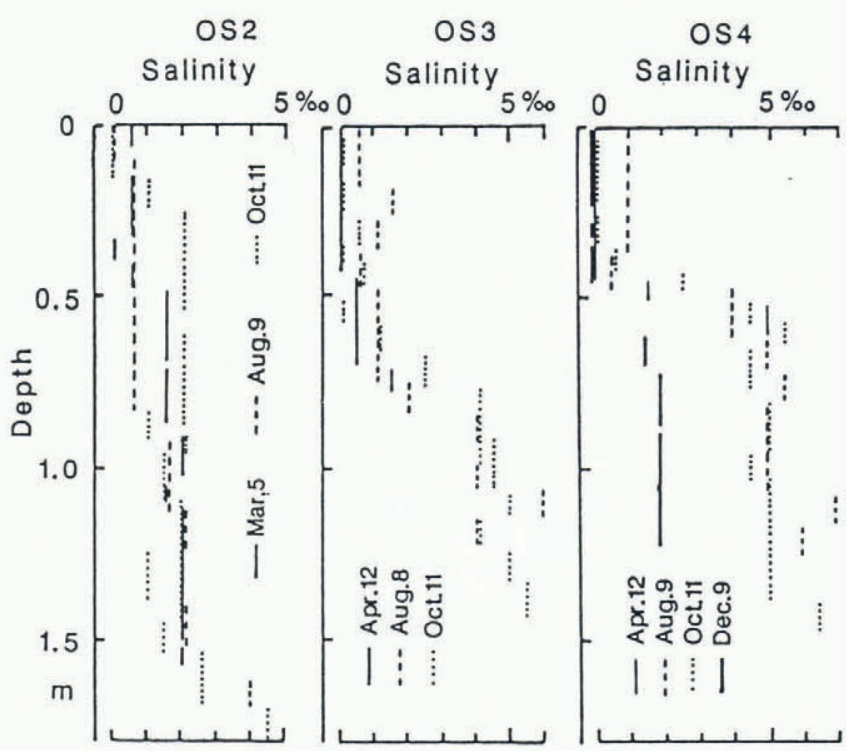

Fig. 5. Salinity profiles of cores collected at OS2, OS3 and OS4 in 1991. 


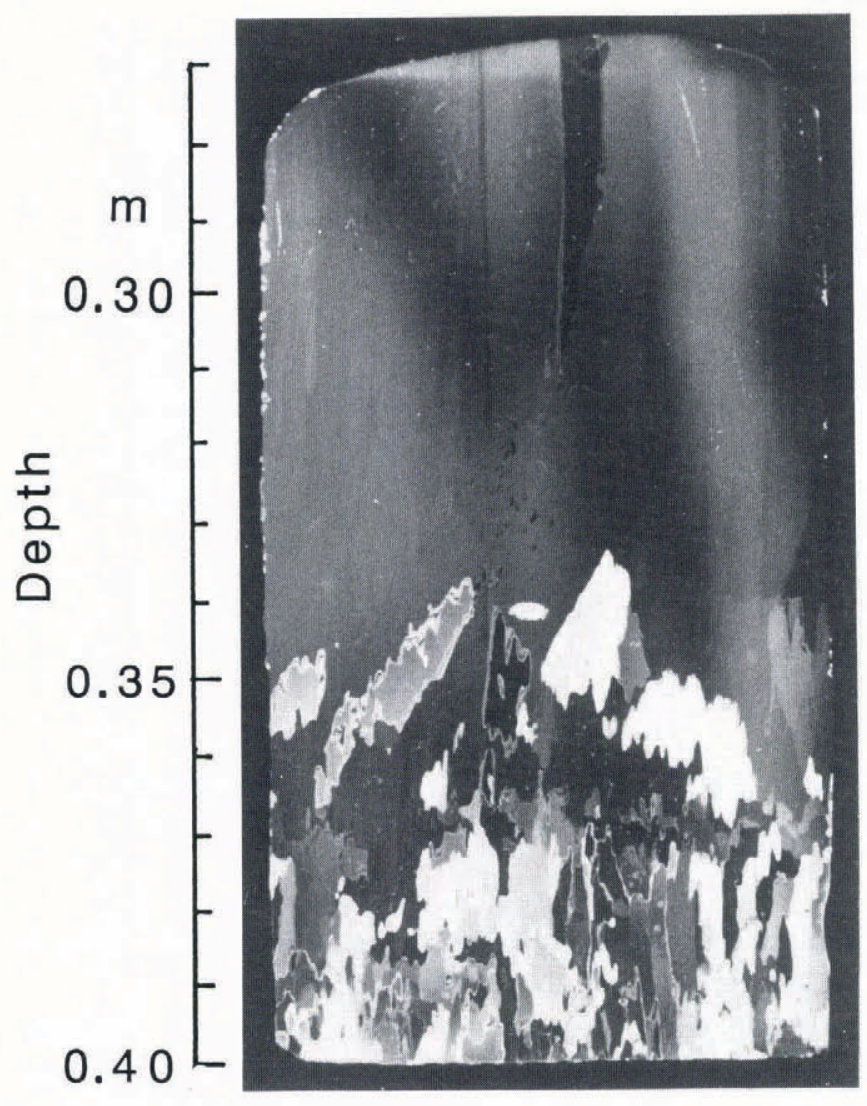

Fig. 6. Vertical thin-section photograph of the core collected on 28 March 1991 at OS4. The upper 0.27-0.34 $m$ of the image represents large "quasi" single crystals underlain by intermediate columnar/granular ice.

The ice core obtained at OS4 on 5 March was composed of columnar ice with some horizontal discontinuous planes. Since the columnar grains had very smooth grain boundaries, did not have the mosaic structure of sea ice, and had a salinity of exactly $0 \%$, the ice was assumed to be made from summer meltwater. Large "quasi" single crystals (Fig. 6), with vertical c-axes and $a$-axes that have shifted a little from each other, were found in the middle part of the core collected on 28 March. This suggests the refreezing of meltwater. The uppermost layer of $0.3-0.4 \mathrm{~m}$ thickness was very transparent and its salinity was close to $0 \%$ throughout the year, implying the freezing of pure water. The structure consisted of not only columnar and single crystalline ice but also intermediate columnar/granular ice, reflecting some difference in the sampling sites.

This uppermost layer was underlain by about $0.2 \mathrm{~m}$ thickness $0 \hat{i}$ intermediate columnar/granular structure with $0.5-2.5 \%$ salinity from the originally diluted water. Columnar ice, with its long, narrow, interlocking crystals aligned parallel to each other, reached to the bottom of the core; this layer was recognized to have an ordinary sea-ice structure, with a salinity of approximately $5 \%$.

Internal melting was found in the 9 December core at the layer about $0.5 \mathrm{~m}$ deep which was underlain by columnar ice. The upper part of the $\sim 0.3 \mathrm{~m}$ thick columnar ice was similar to candle ice, where the grain boundaries are completely melted and the vertical structure of sea ice remains skeleton-like. Salinity of this columnar ice was reduced to about $2 \%$ and temperature was nearly equal to the freezing point. Such internal melting would possibly continue and diminish the sea-ice layer by the end of summer.

Columnar ice prevailed throughout the depths of the core collected at OS3 on 12 April. However, there was a structurally discontinuous plane at a depth of $0.4 \mathrm{~m}$, the upper part being characterized by smooth grain boundaries and very low salinity. On the contrary, the lower part had interlocking grain boundaries and a salinity of $0.5-1.5 \%$, and thus was desalinated sea ice. No marked change was found in the cores taken on 8 April or 11 October, except for additional growth of sea ice with a high salinity $(\sim 5 \%)$. Snow depth was so low at this site that no snow-ice existed.

Various layers were found in the upper part of the core at OS2. Although the structure varied slightly according to the time of sampling, the upper part was made up of the following ice with $\sim 0 \%$ salinity: (1) rounded granular ice with small grains $(1 \mathrm{~mm}$ or less in diameter), (2) vertically elongated granular ice with a diameter of $5 \mathrm{~mm} \times 10 \mathrm{~mm}$, (3) polygonal granular ice, (4) intermediate columnar/granular ice and (5) columnar ice which was occasionally very transparent and had smooth grain boundaries.

The core collected on 9 August is a prime example. The upper $0.1 \mathrm{~m}$ was snow-ice with thin ice plates formed by the freezing of sea water which had entered the snow cover after 12 April (when this ice layer was not observed). The salinity of this layer was very low, since the ice cover at Ongul Strait was multi-year fast ice and then the surface layer of sea water was significantly diluted with meltwater from snow. The existence of an ice

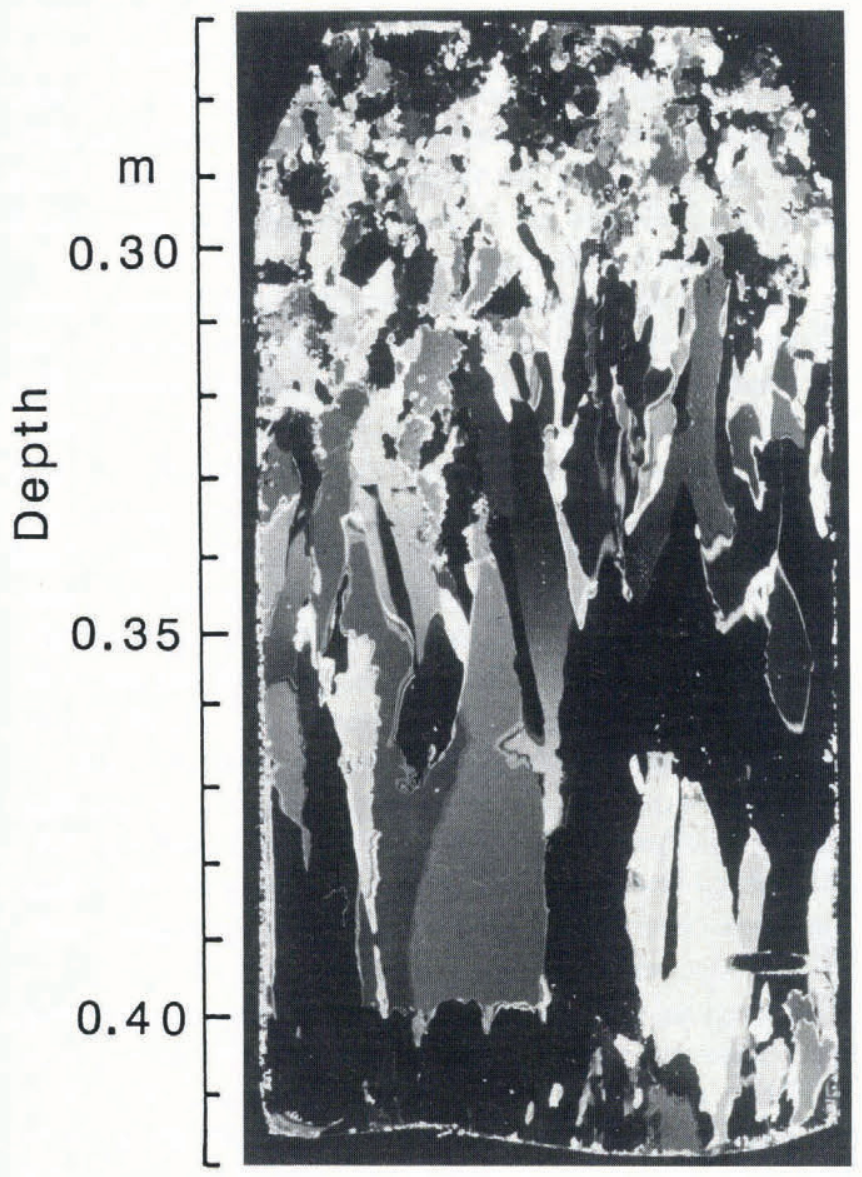

Fig. 7. Photograph of a vertical thin-section from 9 August at OS2. The part below $0.31 \mathrm{~m}$ is columnar ice, which is transparent and has smooth grain boundaries. 
layer with columnar structure (Fig. 7) at $0.31-0.42 \mathrm{~m}$ depth can probably be attributed to the refreezing of meltwater from the snow cover, judging from its transparency and smooth grain boundaries. The layer at $0.10-0.31 \mathrm{~m}$ depth was formed by the refreezing of snow cover permeated by meltwater from snow, and in some layers the retexturing of the ice changed the structure to vertically elongated granular ice. The full thickness of the upper part above the columnar sea ice is comparable to the difference in ice thickness betwen 1990 and 1991. This would, therefore, suggest that snow-ice and ice related to the melting of snow contribute to the increase of ice at this point.

Some interesting snow ice was found at a depth of $0.05-0.10 \mathrm{~m}$ in the core obtained on 10 October. This had extremely small, rounded grains, $<0.5 \mathrm{~mm}$ in diameter, and was very clear because it was made from snow packed very closely by strong winds.

\section{CONCLUSIONS}

We examined the characteristics of the snow and ice cover in Ongul Strait near Syowa Station, Antarctica. Snow depth changes consistently across the strait, increasing with distance from the Antarctic continent. This variation of snow depth affects both the growth and structure of sea ice. The growth rate in winter is lower in a snow-covered region than in a bare-ice region, since higher snow cover inhibits sea-ice growth. However, the ice is thicker in the snow-covered region than in the bare-ice region throughout the year. This result is in contrast to the hypothesis that thick snow cover reduces the vertical heat flux through the ice and the growth rate due to bottom freezing. This contradiction results from sea ice formed by the freezing of water-permeated snow and from ice formation due to snow melting in summer. Sea ice in the snow-covered regions grows in spring rather than in winter. It is most probable that this growth can also be attributed to snow-ice formation. Moreover, the ice thickness decreases drastically in the bare-ice region in summer due to melting at the bottom surface caused by oceanic heat flux and inside the ice due to absorption of solar radiation. On the contrary, the decrease is not so great in the snow-covered regions due to the insulation of heat by the snow cover. Snow cover, therefore, significantly affects the sea-ice growth processes in both the growth and decay seasons.

\section{ACKNOWLEDGEMENTS}

We are greatly indebted to the over-wintering members of the 31 st JARE, led by Professor Y. Naito, and the 32nd JARE, led by Dr Y. Fujii, for their cooperation in the field work.

\section{REFERENCES}

Clarke, D. B. and S. F. Ackley. 1984. Sea ice structure and biological activity in the Antarctic marginal ice zone. 7. Geophys. Res., 89(C2), 2087-2095.

Eicken, H. and M. A. Lange. 1989. Development and properties of sea ice in the coastal regime of the southeastern Weddell Sea. J. Geophys. Res., 94(C6), 8193-8206.

Gow, A.J., S. F. Ackley, W. F. Weeks and J. W. Govoni. 1982. Physical and structural characteristics of Antarctic sea ice. Ann. Glaciol., 3, 113-117.

Lange, M. A. 1988. Basic properties of Antarctic sea ice as revealed by textural analysis of ice cores. Ann. Glaciol., 10, 95-101.

Lange, M. A. and H. Eicken. 1991. The sea ice thickness distribution in the northwestern Weddell Sea. $\mathcal{J}$. Geophys. Res., 96(C3), 4821-4837.

Lange, M. A., S. F. Ackley, P. Wadhams, G. S. Dieckmann and H. Eicken. 1989. Development of sea ice in the Weddell Sea. Ann. Glaciol., 12, 92-96.

Lange, M. A., P. Schlosser, S. F. Ackley, P. Wadhams and G.S. Dieckmann. 1990. ${ }^{18} \mathrm{O}$ concentrations in sea ice of the Weddell Sea, Antarctica. F. Glaciol., 36(124), 315-323.

Wadhams, P., M. A. Lange and S. F. Ackley. 1987. The ice thickness distribution across the Atlantic sector of the Antarctic Ocean in midwinter. 7. Geophys. Res., 92(C13), 14,535-14,552.

The accuracy of references in the text and in this list is the responsibility of the authors, to whom queries should be addressed. 